\title{
Diagnosis of the use of Web 2.0 Tools in the Portuguese Financial Institutions
}

\author{
César Sousa $^{1}$ and Paula Morais ${ }^{1}$ \\ Innovation, Science and Technology Department, Portucalense University, Porto, Portugal \\ cesar_sousa@yahoo.com.br,pmorais@upt.pt
}

Keywords: Web 2.0, Enterprise 2.0, Knowledge Management Practices.

Abstract: Web 2.0 tools helps enterprises to increase innovation. Many organizations seek this kind of tools so they can be competitive in the global world we live today. The Portuguese Financial sector has been very competitive and has used innovation to leverage over competitors. Considering the potential for innovation associated with Web 2.0 and the innovation interest of the sector, it's very relevant to diagnose the level of use of Knowledge Management practices and the adoption of Web 2.0 tools in this sector. This article presents the results of a study aiming to diagnose the level of use of Knowledge Management practices and the adoption of Web 2.0 tools by Portuguese Banks. The study was conducted through a survey sent to all institutions listed in the Portuguese Banking Association, specifically to 26 banks. With a $15.38 \%$ success rate of answers it was possible to infer that in Portugal Knowledge Management practices are present in the Banking sector, as well as the use of Web 2.0 tools, although not with a homogeneous presence.

\section{INTRODUCTION}

In today's dynamic and global business environment, enterprises face ever-increasing pressure to stay competitive and achieve sustainable growth through innovation. The traditional ways of addressing business challenges overlook a rich resource - employees' knowledge. Collaborative Web 2.0 tools enable enterprises to foster employees' critical thinking and creativity while providing a platform to capitalize on their innovations for product and process improvement.

Web 2.0 tools, due to the origin of the concept, are often associated with organizations whose computer based applications have a production platform based on the Internet. The Portuguese financial sector despite being known for its efficiency, competitiveness and innovation is considered a traditional sector, that is, its platform is not based on the Internet.

Considering the potential for innovation associated with Web 2.0 and the innovation interest of the sector, we sought to diagnose the level of use of Knowledge Management (KM) practices and the adoption of Web 2.0 tools by Portuguese Banks.
The study was conducted through a survey sent to all institutions listed in the Portuguese Banking Association, specifically to 26 banks.

From the results it is possible to infer that Knowledge Management practices are present in the Banking sector, as well as the use of Web 2.0 tools, although not with a homogeneous presence.

The paper is divided into three main sections: the first is a brief description of Web 2.0 tools, emphasizing those that are commonly used in organizations. The second section presents the research methodology and the results obtained are discussed in the third section.

\section{BUSINESS IMPACT OF WEB 2.0}

Knowledge Management can be defined as the systematic organization, planning, scheduling, monitoring and deployment of people, processes, technology and environment to facilitate the creation, storage, sharing, and, utilization, of knowledge, in order to improve organizational performance and achieve competitive advantage (Coakes 2004; King 2007). 
It is well known that information technology gives a lot of support to information management, and more recently, different kinds of Knowledge Management systems have emerged, in order to support Knowledge Management processes; for instance knowledge maps, collaboration systems, workflow systems, competence management systems, corporative portals, business intelligence systems (Pinto et al. 2005).

Knowledge is socially constructed, it is created through discourse in "ba" that is the physical, mental and/or virtual arena of knowledge creation (Nonaka $\&$ Konno 1998). How can information technology support this kind of socially construction? Social media tools can give a substantial contribution to this process.

Social media tools have come to be known as Web 2.0, term closely associated with Tim O'Reilly (Tim O'Reilly \& Battelle 2009).

The term Web 2.0 has been used in many different ways, it refers to a second generation of Internet-based tools - such as wikis, blogs, social networking, social bookmarking, tagging, mashups and folksonomies - that emphasize online collaboration and sharing among users (Sutter 2009; Raman 2009).

Web 2.0 originally described tools that were primarily used in the web by single users. Why are these tools particularly noteworthy? They are significant because they can potentially increase knowledge creation and sharing among organization members, making knowledge available to those who need it. They provide a platform for Knowledge Management (King 2007). In a highly globalized world, new ways to cultivate and exploit knowledge sharing with customers, suppliers and partners are forcing companies to expand their KM concept and agenda (Mentzas et al. 2007). We can talk about a second phase of Knowledge Management where companies try to exploit a much richer form of knowledge assets, using Web 2.0 tools and focusing on the social, collaborative dimension of the Web (Kirchner et al. 2009).

Recently there have been some research works to understand the potential of Web 2.0 for business in different domains, discovering how organizations are using these tools in pursuit of their missions (Chui et al. 2012; Raeth et al. 2010; Andriole 2010; Bughin et al. 2008, Matuszak 2007).

Matuszak (2007), from KPMG, describes a survey conducted across a range of industries about the adaption of "enterprise 2.0" technologies. This study shows that "enterprise 2.0" adaption could offer benefits like fostering collaboration, innovation and enhance productivity. Some respondents also refer challenges and barriers that must be addressed before their organizations can take the full potential of these new tools. Security risks and governance issues were referred.

Bughin et al. (2008) work focuses on McKinsey's second annual survey on the business use of Web 2.0 technologies: which of these social and interactive tools the companies have adopted and for which purposes, what executives are doing to encourage adoption, and how satisfied they are with their use of these tools. The survey reveals continuing investments in Web 2.0, but also suggests that after an initial period of promise and trial, companies are coming to understand the difficulty of realizing some of Web 2.0's benefits. Only 21 percent of the respondents say they are satisfied overall with these tools.

The work from Raeth et al. (2010), explores the processes of Web 2.0 technologies' adoption in companies, focusing on identifying how and why Web 2.0 systems are deployed, comparing the process with enterprise system adoption projects.

The article from Andriole (2010) describes research designed to measure the impact of the business value of web 2.0 technologies in selected companies and industries primarily in the U.S.; the results showed that Web 2.0 technologies can help improve collaboration and communication within most companies, though many companies are cautious about deploying them. The work also shows concerns about intellectual property, proprietary information, privacy, security, and control.

The report from Chio et al. (2012) explores the potential economic impact of the use of social technologies, by examining their current usage and evolving application. It is referred, in this report, that 72 percent of companies use social technologies in some way, very few are anywhere near to achieve the full potential benefit. It also concludes that to get the full benefit of those technologies, organizations must transform their structures, processes, and cultures: they will need to create a culture of trust and improve the participation of employees that should not be afraid of sharing their thoughts and trust that their contributions will be respected.

In spite of the growing interest in using those technologies, significant problems with the implementation and acceptance of Web 2.0 tools exist in organizations. Particularly in regulated areas like financial services, serious challenges can appear when it comes to engaging with the world via social media. 


\section{RESEARCH METHODOLOGY}

The main objective of the research described in this paper is to understand the business impact of Web 2.0 tools and Knowledge Management practices in financial organizations. The banking sector was chosen considering that it operates in a mature and competitive market and has become an industry innovator and also a pioneer in the use of technologies and management methodologies. But considering the concerns about proprietary information, privacy, security, and control, the challenges that can appear when it comes to use social media tools in this sector, can be relevant.

A quantitative study was made through a questionnaire sent to all institutions listed in the Portuguese Banking Association, in 2009, specifically to 26 banks.

The questionnaire was developed, with the aim of identifying the KM organizational practices carried out, related to the creation, sharing, storage and use of knowledge and to diagnose the level of use of such practices. It was also intended to identify the level of use and implementation of Web 2.0 tools.

The questionnaire was structured in two blocks. The first refers to the issues related to Knowledge Management practices and the second to the issues related to Web 2.0 tools.

The first block is subdivided into five groups related to KM practices: Policies and Strategies; Leadership; Incentives; Knowledge capture and acquisition and Training and Learning. This structure was based on the questionnaire used in the study "Pilot Knowledge Management Practices Survey," (CFL 2002). This questionnaire uses a list of practices which can be used in Knowledge Management, taken as representative of what is considered best practice. This same questionnaire was also used by Almeida (2007) in a work that sought to identify, from a list of 23 Knowledge Management initiatives, which ones were the most and the less used; it was carried out in small and medium size enterprises (SMEs) in the northern region of Portugal.

The second block begins with two questions about employees' Internet access and Intranet use in the organization. The next seven questions aim to identify the Web 2.0 tools used by the organizations through the Web 2.0 components (McAfee, 2006). The last group of questions aims to find out the degree of use of these tools.

All the questions considered five alternative answers: 1: Yes, before 2007; 2: Yes, after 2007; 3 :
No; 4: No, but intend to use in the next 24 months; 5: Does not know.

In December 2009 questionnaires were sent via e-mail addresses to the 26 banks. At the same time questionnaires were sent directly to four employers personal e-mail addresses, obtained through direct contacts of one of the author of this study that works in this sector.

All questionnaires sent to general addresses had no answer. All the direct contacts got answers, giving a success rate of $15.38 \%$. It must be emphasized that responses came from four out of five largest national banks in terms of market share in both loans and deposits from customers. All people who answered to the questionnaire are male, graduates and holding positions of leadership in the organizations.

\section{RESEARCH RESULTS}

The results were analyzed using Microsoft Excel and SPSS for Windows. Table 1 presents the average values related to Knowledge Management practices and table 2 presents the results related to Web 2.0 tools.

Considering the specificities of the sector it was considered appropriate to compare the results with those reported by Almeida (2007), which discusses the use of KM practices, but in Portuguese SMEs; we concluded that the average values in banks are higher than in the SMEs. Is noteworthy to know SMEs are more than $90 \%$ of Portuguese enterprises.

It was also concluded the Intranets are more available in banks than in SME companies. On the other hand, although the investigation submitted in banks shows a greater access to the Internet, statistically speaking the difference is not significant.

The institutions believe they have good systems for information search. The use of warning systems and content authoring systems was also a reality, although not with a significant existence in the surveyed institutions. 


\section{Portuguese Banks}

\begin{tabular}{|c|c|c|c|c|c|}
\hline \multirow{2}{*}{ KM Practices } & \multirow{2}{*}{ Average } & \multirow{2}{*}{$\begin{array}{l}\text { Standard } \\
\text { deviation }\end{array}$} & \multicolumn{3}{|c|}{ Confidence Interval $=95 \%$} \\
\hline & & & \begin{tabular}{|l|} 
Confidence \\
\end{tabular} & from & until \\
\hline \multicolumn{6}{|l|}{ Policies and Strategies - Your firm or organisation: } \\
\hline has a values system or culture intended to promote knowledge sharing & 2,75 & 0,50 & 0,80 & 1,95 & 3,55 \\
\hline has policies or programs intended to improve worker retention & 2,03 & 1,37 & 2,18 & $-0,15$ & 4,20 \\
\hline uses partnerships or strategic alliances to acquire knowledge & 2,28 & 1,45 & 2,31 & $-0,03$ & 4,58 \\
\hline \multicolumn{6}{|l|}{ Leadership - In your firm or organisation knowledge management practices are: } \\
\hline a responsibility of managers and executives & 3 & 0,00 & 0,00 & 3,00 & 3,00 \\
\hline a responsibility of non-management workers & 2,00 & 1,41 & 2,25 & $-0,25$ & 4,25 \\
\hline a responsibility of the knowledge officer or knowledge management unit & 3,00 & 0,00 & 0,00 & 3,00 & 3,00 \\
\hline explicit criteria for assessing worker performance & 2,25 & 1,50 & 2,39 & $-0,14$ & 4,64 \\
\hline \multicolumn{6}{|l|}{ Incentives - Your firm or organisation specifically rewards knowledge sharing with: } \\
\hline monetary incentives & 1,50 & 1,73 & 2,76 & $-1,26$ & 4,26 \\
\hline non-monetary incentives & 1,5 & 1,73 & 2,76 & $-1,26$ & 4,26 \\
\hline \multicolumn{6}{|l|}{ Knowledge capture and acquisition - Your firm or organisation regularly: } \\
\hline captures and uses knowledge obtained from other industry sources such as industrial asso & 3,00 & 0,00 & 0,00 & 3,00 & 3,00 \\
\hline captures and uses knowledge obtained from public research institutions including universit & 2,28 & 1,45 & 2,31 & $-0,03$ & 4,58 \\
\hline dedicates resources to detecting and obtaining external knowledge and communicating it $\mathrm{W}$ & 3 & 0,00 & 0,00 & 3,00 & 3,00 \\
\hline encourages workers to participate in project teams with external experts & 3,00 & 0,00 & 0,00 & 3,00 & 3,00 \\
\hline \multicolumn{6}{|l|}{ 1.5 Training and Learning - Your firm or organisation: } \\
\hline provides formal training related to knowledge management practices & 2,28 & 1,45 & 2,31 & $-0,03$ & 4,58 \\
\hline provides informal training related to knowledge management & 2,28 & 1,45 & 2,31 & $-0,03$ & 4,58 \\
\hline uses formal mentoring practices, including apprenticeships & 2,25 & 1,50 & 2,39 & $-0,14$ & 4,64 \\
\hline encourages experienced workers to transfer their knowledge to new or less experienced w & 3 & 0,00 & 0,00 & 3,00 & 3,00 \\
\hline encourages workers to continue their education by reimbursing tuition fees for successfull & 3,00 & 0,00 & 0,00 & 3,00 & 3,00 \\
\hline offers off-site training to workers in order to keep skills current & 3,00 & 0,00 & 0,00 & 3,00 & 3,00 \\
\hline
\end{tabular}

Table 1: KM practices average values

\section{Portuguese Banks}

\begin{tabular}{|c|c|c|c|c|c|}
\hline \multirow[t]{2}{*}{ Web 2.0 components } & \multirow{2}{*}{ Average } & \multirow{2}{*}{$\begin{array}{l}\text { Standard } \\
\text { deviation }\end{array}$} & \multicolumn{3}{|c|}{ Confidence Interval $=\mathbf{9 5 \%}$} \\
\hline & & & Confidence & from & until \\
\hline Your organization & & & & & \\
\hline Search - It has an easier information search system? & 2,75 & 0,50 & 0,80 & 1,95 & 3,55 \\
\hline $\begin{array}{l}\text { Extensions - It has applications with search engines that as well as providing the information requested, also } \\
\text { recommends similar information? }\end{array}$ & 0,75 & 1,50 & 2,39 & $-1,64$ & 3,14 \\
\hline Signals - It has applications that alert users of its news content? & 1,75 & 1,26 & 2,00 & $-0,25$ & 3,75 \\
\hline Authoring - It has applications where users can enter and share information? & 1,75 & 1,26 & 2,00 & $-0,25$ & 3,75 \\
\hline Links - Allows users to create hyperlinks between pages of the intranet and / or other applications? & 0 & 0,00 & 0,00 & 0,00 & 0,00 \\
\hline Tags - It has tools in the applications that allow users to sort and / or organize the content? & 0,78 & 1,48 & 2,36 & $-1,59$ & 3,14 \\
\hline Some of these Web 2.0 features in previous questions (queries, recommendations, alerts, etc.) are present & & & & & \\
\hline In your organization webpage? & 1,25 & 1,50 & 2,39 & $-1,14$ & 3,64 \\
\hline In the applications within the organization and are used by most users? & 2,00 & 1,41 & 2,25 & $-0,25$ & 4,25 \\
\hline In the applications within the organization but are little used? & 0,00 & 0,00 & 0,00 & 0,00 & 0,00 \\
\hline Only in one department or not present in organization most important departments? & 0,53 & 0,98 & 1,57 & $-1,04$ & 2,09 \\
\hline In several departments or essencially in the most important departments? & 2,50 & 0,58 & 0,92 & 1,58 & 3,42 \\
\hline
\end{tabular}

Table 2: Web 2.0 tools in Portuguese banks 


\section{CONCLUSIONS}

This study allows inferring that Knowledge Management practices exist in the banking sector, and that Web 2.0 is also present, although there is no uniformity in its use.

It can also be noticed that practices related to knowledge capture and acquisition are most common, together with practices related to the increase of workers skills, that is, knowledge creation.

Web 2.0 tools can improve knowledge sharing and are mostly used internally and not widely used in banks' websites, probably due to the characteristics of these organizations. This sector is ruled by bank secrecy and characterized by the high use of information control.

For future study, our research will be directed to understand how the next generation of proactive, contextual and adaptive web tools, will drive further innovation in the financial sector, overcoming the challenges of privacy, security and proprietary information.

The new direction for the mobile network opens enormous new possibilities for business. The study of how the adoption of these tools will affect banks is another direction for future research.

\section{REFERENCES}

Almeida, G.F. de O.C. de, 2007. Diagnóstico da maturidade da gestão do conhecimento nas pequenas $e$ médias empresas portuguesas. Universidade do Minho. Available at: http://repositorium.sdum.uminho.pt/bitstream/1822/70 30/1/Tese.pdf.

Andriole, S., 2010. Business Impact of Web 2.0 technologies. Communications of the ACM, 53(12), p.67-79.

Bughin, J.; Manyika, J.; Miller, A. 2008. Building the Web 2.0 Enterprise. Available at: http://download.mckinseyquarterly.com/Web2.0.pdf

Chui, M., Manyika, J., Bughin, J., Dobbs, R., Roxburg, C., Sarrazin, H., Sands, G., Westergren, M. 2012. The social economy: Unlocking value and productivity through social technologies. Available at: http://www.mckinsey.com/insights/mgi/research/techn ology_and_innovation/the_social_economy

CFL, C. for L. 2002, OECD Knowledge Management project Report - Danish pilot-survey, Available at: http://www.oecd.org/dataoecd/23/56/2756535.pdf.
Coakes, E., 2004. Knowledge Management - a Primer. Communications of the Association for Information Systems, 14, p.406-489.

King, W.R., 2007. Keynote paper: knowledge management: a systems perspective. International Journal of Business Systems and Research, 1(1), p.528.

Kirchner, K., Razmerita, L., \& Sudzina, F. 2009. New Forms of Interaction \& Knowledge Sharing on Web 2.0. In M. D. Lytras, E. Damiani \& P. O. d. Pablos (Eds.), Web 2.0 The Business Model. New York: Springer

McAfee, A. P. 2006. Enterprise 2.0: The Dawn of Emergent Collaboration. MIT Sloan Management Review(Spring 2006), 21-24

Matuszak, G., 2007. Enterprise 2.0: the benefits and challenges of adoption, Available at: www.kpmg.com

Mentzas, G., Kafentzis, K., \& Georgolios, P. 2007. Knowledge services on the semantic Web Comunications of the ACM, 10(50), 53-58

Nonaka, I. \& Konno, N., 1998. The concept of "Ba": Building a foundation for knowledge creation. In California Management Review. pp. 40-54.Use the "Insert Citation" button to add citations to this document.

Pinto, M.P., Castro, F. \& Morais, M.P., 2005. A Framework for Characterizing Knowledge Management Systems. In European Conference on Knowledge Management (ECKM 2005).

Raman T. V., 2009. Toward $2^{w}$, beyond web 2.0. Communications of the ACM, 52(2).

Raeth, P. et al., 2010. The Adoption of Web 2.0 in Corporations: A Process Perspective. In Americas Conference on Information Systems. Available at: http://aisel.aisnet.org/amcis2010/405.

Sutter, J., 2009. Tutorial: Introduction to Web 2.0. Communications of the Association for Information Systems, 25(1).

Tim O'Reilly \& Battelle, J., 2009. Web Squared: Web 2.0 Five Years On. Available at: http://assets.en.oreilly.com/1/event/28/web2009_webs quared-whitepaper.pdf. 